\title{
Characteristics and survival of patients with advanced cancer and p53 mutations
}

\author{
Rabih Said ${ }^{1,2}$, Yang Ye ${ }^{1}$, David S. Hong ${ }^{1}$, Filip Janku ${ }^{1}$, Siqing Fu ${ }^{1}$, Aung Naing ${ }^{1}$, \\ Jennifer J. Wheler ${ }^{1}$, Razelle Kurzrock ${ }^{1,3}$, Christoforos Thomas ${ }^{4}$, Gary A. Palmer ${ }^{5}$, \\ Kenneth R. Hess ${ }^{6}$, Kenneth Aldape ${ }^{7}$ and Apostolia M. Tsimberidou ${ }^{1}$ \\ ${ }^{1}$ Department of Investigational Cancer Therapeutics (Phase I Clinical Trials Program), The University of Texas MD Anderson \\ Cancer Center, Houston, TX \\ ${ }^{2}$ Department of Internal Medicine, Oncology Division, The University of Texas Health Sciences Center, Houston, TX \\ ${ }^{3}$ Center for Personalized Therapy and Clinical Trials, University of California San Diego - Moores Cancer Center, San Diego, \\ CA \\ ${ }^{4}$ Department of Biology and Biochemistry, University of Houston, Houston, Texas \\ ${ }^{5}$ Foundation Medicine, Cambridge, MA \\ ${ }^{6}$ Department of Biostatistics, The University of Texas MD Anderson Cancer Center, Houston, TX \\ 7 Department of Pathology, The University of Texas MD Anderson Cancer Center, Houston, TX \\ Correspondence to: Apostolia-Maria Tsimberidou, email: atsimber@mdanderson.org \\ Keywords: p53 mutations, matched therapy, molecular aberrations
}

Received: February 21, $2014 \quad$ Accepted: May 23, $2014 \quad$ Published: May 25, 2014

This is an open-access article distributed under the terms of the Creative Commons Attribution License, which permits unrestricted use, distribution, and reproduction in any medium, provided the original author and source are credited.

\section{ABSTRACT}

P53 mutations are associated with invasive tumors in mouse models. We assessed the p53 mutations and survival in patients with advanced cancer treated in the Phase I Program. Of 691 tested patients, 273 (39.5\%) had p53 mutations. Patients with p53 mutations were older $(p<.0001)$ and had higher numbers of liver metastases $(p=.005)$. P53 mutations were associated with higher numbers of other aberrations; PTEN $(p=.0005)$ and HER2 $(p=.003)$ aberrations were more common in the p53 mutation group. No survival difference was observed between patients with p53 mutations and those with wild-type p53. In patients with wild-type p53 and other aberrations, patients treated with matched-therapy against the additional aberrations had longer survival compared to those treated with non-matched-therapy or those who received no therapy (median survival, 26.0 vs. 11.8 vs. 9.8 months, respectively; $p=.0007)$. Results were confirmed in a multivariate analysis $(p=.0002)$. In the p53 mutation group with additional aberrations, those who received matchedtherapy against the additional aberrations had survival similar to those treated with non-matched-therapy or those who received no therapy $(p=.15)$. In conclusion, our results demonstrated resistance to matched-targeted therapy to the other aberrations in patients with p53 mutations and emphasize the need to overcome this resistance.

\section{INTRODUCTION}

The tumor suppressor protein p53 is activated in response to a variety of stress signals to ensure genome stability in cells. The role of p53 in guarding the cell reflects its ability to act as a potent transcriptional activator, regulating the expression of genes that inhibit cell cycle progression or induce apoptosis or senescence. By eliciting cell growth inhibition, p53 functions to prevent cancer development [1]. In addition to its role in suppressing tumor growth, p53 can limit cancer progression by decreasing the invasiveness and metastatic capacity of cancer cells [2-4].

Loss of p53 function occurs frequently in human cancers and results from mutations in the p53 gene or defects in the pathway that activates p53 [1]. More than $75 \%$ of p53 mutations lead to the expression of a fulllength protein with a single amino acid substitution. 
Table 1a: Characteristics of patients with wild-type and mutant p53 tumors

\begin{tabular}{|l|l|l|l|l|}
\hline & $\begin{array}{l}\text { P53 mutation } \\
\text { N=273 } \%)\end{array}$ & $\begin{array}{l}\text { P53 wild-type } \\
\text { N=418 (\%) }\end{array}$ & $\begin{array}{l}\text { Total } \\
\text { N=691 (\%) }\end{array}$ & p-value \\
\hline Sex & & & & .2 \\
\hline Female & $141(52)$ & $236(56)$ & $377(55)$ & \\
\hline Male & $132(48)$ & $182(44)$ & $314(45)$ & \\
\hline Age & & & & .01 \\
\hline$>60$ & $130(48)$ & $159(38)$ & & \\
\hline Race & & & & .6 \\
\hline White & $207(76)$ & $318(76)$ & $525(76)$ & \\
\hline Hispanic & $29(11)$ & $37(9)$ & $66(10)$ & \\
\hline Black & $27(10)$ & $39(9)$ & $66(10)$ & \\
\hline Asian & $8(2)$ & $18(4)$ & $26[16]$ & \\
\hline Unknown & $2(1)$ & $6(2)$ & $8(1)$ & \\
\hline Tumor type & & & & NA \\
\hline CRC & $49(18)$ & $52(12)$ & $101(15)$ & \\
\hline Ovarian & $31(11)$ & $27(7)$ & $58(8)$ & \\
\hline GI, other & $29(11)$ & $28(7)$ & $57(8)$ & \\
\hline Breast & $22(8)$ & $43(10)$ & $65(9)$ & \\
\hline GYN, other & $18(7)$ & $17(4)$ & $35[16]$ & \\
\hline Lung & $18(7)$ & $22[16]$ & $40(6)$ & \\
\hline Genitourinary & $17(6)$ & $29(8)$ & $46(7)$ & \\
\hline Head and neck & $15[16]$ & $53(12)$ & $68(10)$ & \\
\hline Sarcoma & $9[16]$ & $45(11)$ & $54(8)$ & \\
\hline Endometrial & $9[16]$ & $12[16]$ & $21[16]$ & \\
\hline Melanoma & $8[16]$ & $22[16]$ & $30(4)$ & \\
\hline Pancreatic & $5(2)$ & $9(2)$ & $14(2)$ & \\
\hline Thyroid & $4(1)$ & $9(2)$ & $13(2)$ & \\
\hline Other & $39(14)$ & $50(12)$ & $89(13)$ & \\
\hline ECOG score & & & & .23 \\
\hline 0 & $69(25)$ & $128(31)$ & $197(29)$ & \\
\hline 1 & $180(66)$ & $247(59)$ & $427(62)$ & \\
\hline 2 & $19(7)$ & $35(8)$ & $54(8)$ & \\
\hline 3 & $2(1)$ & $7(-)$ & $9(1)$ & \\
\hline Unavailable & & & & \\
\hline & & & & \\
\hline & & & & \\
\hline & & & & \\
\hline
\end{tabular}

In most cases, these mutant p53 proteins lose wildtype functions, elicit dominant-negative effects on the remaining wild-type $\mathrm{p} 53$, or acquire oncogenic functions [5-7]. This gain-of-function phenotype has been characterized in in vivo studies. Mice that carry mutant p53 develop different types of tumors with more invasive phenotypes than the p53-null mice in which the p53 protein is not expressed $[6,8]$. In addition, the analysis of cell culture models has identified several oncogenic properties of mutant $\mathrm{p} 53$, including its ability to promote migration, invasion, angiogenesis, and chemoresistance $[2-4,7,9,10]$. The single amino acid substitutions in the p53 protein are divided into two broad classes: structural and contact DNA mutations. Most of the point mutations, including those at amino acids R175, G245, R248, R249, R273 and R282, tend to cluster at hot spots within the DNA-binding domain. Contact hot spot mutations lead to the loss of DNA binding activity and subsequent alterations in the transcriptional activity of $\mathrm{p} 53$. Structural hot spot mutations cause unfolding of the $\mathrm{p} 53$ protein that affects its interaction with other proteins. Mutant p53 has been shown to elicit its oncogenic actions by interacting with and inhibiting its family members, p63 and p73. Mutant p53 is known to alter the expression of p63 target genes, and this has been associated with enhanced invasive behavior [7]. In addition, oncogenic mutations that activate the Ras signaling pathway inhibit the function of $\mathrm{p} 63$ by promoting its interaction with mutant $\mathrm{p} 53$. By regulating the activity of mutant $\mathrm{p} 53$, oncogenic Ras induces the development of prometastatic phenotypes[11, 12].

Several studies have investigated the importance of p53 mutation status in predicting clinical outcome in various types of cancer. Some of the p53 mutations have 
Table 1b: Characteristics of patients with wild-type and mutant p53 tumors

\begin{tabular}{|c|l|l|l|l|}
\hline Albumin & & & & .55 \\
\hline$\geq 3.5 \mathrm{~g} / \mathrm{dL}$ & $238(87)$ & $369(88)$ & $607(87)$ & \\
\hline$<3.5 \mathrm{~g} / \mathrm{dL}$ & $26(10)$ & $47(11)$ & $73(10)$ & \\
\hline Unavailable & $9[16]$ & $4(1)$ & $23[16]$ & \\
\hline $\mathrm{LDH}$ & & & & .35 \\
\hline$>618 \mathrm{U} / \mathrm{L}$ & $90(33)$ & $128(31)$ & 218 & \\
\hline$\leq 618 \mathrm{U} / \mathrm{L}$ & $172(63)$ & $286(68)$ & 458 & \\
\hline Unavailable & $11(4)$ & $4(14)$ & 27 & \\
\hline RMH score & & & & .59 \\
\hline 0 & $126(46)$ & $212(51)$ & $338(49)$ & \\
\hline 1 & $87(32)$ & $123(29)$ & $210(30)$ & \\
\hline 2 & $42(16)$ & $69(17)$ & $111(16)$ & \\
\hline 3 & $6(2)$ & $9(2)$ & $15(2)$ & \\
\hline Unknown & $12(4)$ & $5(1)$ & $17[16]$ & \\
\hline Liver metastases & $108(40)$ & $122(29)$ & $230(33)$ & .005 \\
\hline $\begin{array}{l}\text { Number of metastatic } \\
\text { sites }\end{array}$ & & & \\
\hline Median (Range) & $2(0-8)$ & $2(0-7)$ & $2(0-8)$ & .15 \\
\hline $\begin{array}{l}\text { Number of prior } \\
\text { therapies }\end{array}$ & & & & \\
\hline Median (Range) & $3(0-10)$ & $3(0-13)$ & $3(0-10)$ & .16 \\
\hline
\end{tabular}

Abbreviations: CRC-colorectal, GI-gastrointestinal, GYN-gynecological, ECOG-Eastern Cooperative Oncology Group, LDH-lactate dehydrogenase, RMH-Royal Marsden Hospital.

been correlated with shorter survival or a poorer response to treatment in several cancers[13]. In addition, some mutations were correlated with worse survival than other mutations. For example, mutations in the DNA-binding domain of p53 have been associated with worse prognosis and poorer response to chemotherapy [14].

We have previously reported the clinical characteristics and response to standard systemic therapy of 145 patients with documented p53 mutational status ( $\mathrm{n}=66$ mutated vs. $\mathrm{n}=79$ wild-type tumors) who were referred to our department for participation in Phase I clinical trials[15]. In the current study, we assessed the frequency of various p53 mutations and their effects on clinical outcomes in a larger number of patients with advanced cancer who were referred for treatment to the Phase I Clinical Trials Program at The University of Texas MD Anderson Cancer Center. We also evaluated the impact on clinical outcomes of additional targetable aberrations in patients with and without p53 mutations.

\section{RESULTS}

\section{Demographics}

From May 2010 to April 2013, 691 patients were found to have tumor tissue tested for p53 mutation status. Of these, 273 (39.5\%) had p53 mutations and 418 (60.5\%) had wild-type p53. The patients' baseline characteristics by $\mathrm{p} 53$ mutation status are shown in Table 1a and Table 1b. Patients with p53 mutations were older (median age, 59 vs. 55 years, $\mathrm{p}<.0001)$ and were more likely to have liver metastases $(108 / 273$ [33\%] vs. 122/418 [29\%], $\mathrm{p}=.005$ ) compared to patients with wild-type $\mathrm{p} 53$.

No difference between the two groups was observed in sex, race, performance status, number of metastatic sites, number of prior therapies, serum albumin and lactate dehydrogenase levels, and Royal Marsden Hospital score. The most common tumor types seen were colorectal, head and neck, and breast cancers, which reflected the referral pattern of patients in the Phase I Clinic. Colorectal cancer was the most common malignancy in both groups (wildtype, $\mathrm{n}=49$ [18\%] and mutant, $\mathrm{n}=52$ [12.5\%]).

\section{Distribution of p53 Mutations}

Of 273 patients with p53 mutations, $17(6 \%)$ had more than one p53 mutation. The distribution of p53 mutations by exons, codons, and tumor types is summarized in Table 2. Of the 273 patients, 239 (84\%) had mutations within the DNA-binding domain, with the following distribution: exon $5(\mathrm{n}=73,27 \%)$, exon $6(\mathrm{n}=45$, $16 \%)$, exon $7(n=63,23 \%)$, and exon $8(n=58,21 \%)$. Mutations within other exons were found in $47(17 \%)$ patients. P53 mutations within exon 5 were more common in colorectal cancer, whereas mutations within exons 6,7 , and 8 were more common in lung, pancreatic, and ovarian cancer, respectively. Mutations within other exons were more common in various gynecological, breast, and 
Table 2: Distribution of p53 mutations by exons, codons, and tumor types

\begin{tabular}{|c|c|c|c|c|c|c|c|c|}
\hline \multirow[b]{2}{*}{ Cancer type } & \multicolumn{5}{|c|}{ Exon Location* } & \multicolumn{3}{|c|}{ Codon Location* } \\
\hline & \begin{tabular}{|l|} 
Exon \\
$5(\%)$ \\
\end{tabular} & $\begin{array}{l}\text { Exon } \\
6(\%) \\
\end{array}$ & \begin{tabular}{|l|} 
Exon \\
$7(\%)$ \\
\end{tabular} & \begin{tabular}{|l|} 
Exon \\
$8(\%)$ \\
\end{tabular} & \begin{tabular}{|l} 
Others \\
$(\%)$
\end{tabular} & Hot-spot (\%) & $\begin{array}{l}\text { DNA-binding, } \\
\text { excluding hotspot (\%) }\end{array}$ & \begin{tabular}{|l|}
$\begin{array}{l}\text { Others } \\
(\%)\end{array}$ \\
\end{tabular} \\
\hline Colorectal $(\mathrm{n}=49)$ & $\begin{array}{l}16 \\
(33)\end{array}$ & $6(12)$ & $\begin{array}{l}11 \\
(22)\end{array}$ & $\begin{array}{l}10 \\
(20)\end{array}$ & $7(14)$ & $24(49)$ & $20(41)$ & $5(10)$ \\
\hline Ovarian $(n=31)$ & $9(29)$ & $4(13)$ & $4(13)$ & \begin{tabular}{|l|l|}
10 \\
$(32)$
\end{tabular} & $4(13)$ & $7(23)$ & $21(68)$ & $3(10)$ \\
\hline GI, other $(n=29)$ & $9(31)$ & $2(7)$ & \begin{tabular}{|l|}
10 \\
$(35)$ \\
\end{tabular} & $7(24)$ & $4(14)$ & $8(28)$ & $22(76)$ & $2(7)$ \\
\hline Lung $(n=18)$ & $6(33)$ & $6(33)$ & $2(11)$ & $2(11)$ & $2(11)$ & $3(17)$ & $13(72)$ & $2(11)$ \\
\hline Genitourinary $(\mathrm{n}=17)$ & $3(18)$ & $3(18)$ & $4(23)$ & $4(23)$ & $4(23)$ & $4(24)$ & $10(59)$ & $4(24)$ \\
\hline GYN, other $(n=18)$ & $2(11)$ & $4(22)$ & $3(17)$ & $5(28)$ & $4(22)$ & $6(33)$ & $9(50)$ & $3(16)$ \\
\hline Head and neck $(n=15)$ & $3(20)$ & $4(26)$ & $4(26)$ & $2(13)$ & $3(20)$ & $3(20)$ & $12(80)$ & $2(13)$ \\
\hline Breast $(\mathrm{n}=22)$ & $7(32)$ & $2(9)$ & $3(14)$ & $5(23)$ & $6(27)$ & $6(27)$ & $14(64)$ & $5(23)$ \\
\hline Sarcoma $(n=9)$ & $3(33)$ & $1(11)$ & 0 & $3(33)$ & $2(22)$ & $1(11)$ & $6(66)$ & $2(22)$ \\
\hline Endometrial $(n=9)$ & $3(33)$ & $1(11)$ & $4(44)$ & \begin{tabular}{|l|l|}
0 \\
\end{tabular} & $1(11)$ & $3(33)$ & $5(56)$ & $1(11)$ \\
\hline Melanoma $(\mathrm{n}=8)$ & $2(25)$ & $4(50)$ & $1(12)$ & 0 & $2(25)$ & $2(25)$ & $6(75)$ & $2(25)$ \\
\hline Pancreatic $(\mathrm{n}=5)$ & \begin{tabular}{|l|l|}
0 \\
\end{tabular} & $1(20)$ & $3(60)$ & $1(20)$ & 0 & $2(40)$ & $3(60)$ & 0 \\
\hline Thyroid $(\mathrm{n}=4)$ & 0 & 0 & $1(25)$ & $2(50)$ & $1(25)$ & $1(25)$ & $2(50)$ & $1(25)$ \\
\hline Other $(\mathrm{n}=39)$ & $\begin{array}{l}10 \\
(26)\end{array}$ & $7(18)$ & \begin{tabular}{|l|}
13 \\
$(33)$ \\
\end{tabular} & $8(20)$ & $7(18)$ & $10(26)$ & $26(67)$ & $7(18)$ \\
\hline Total $(n=273)$ & $\begin{array}{l}73 \\
(27)\end{array}$ & \begin{tabular}{|l}
45 \\
$(16)$
\end{tabular} & \begin{tabular}{|l|}
63 \\
$(23)$
\end{tabular} & $\begin{array}{l}59 \\
(22)\end{array}$ & $47(17)$ & $80(29)$ & $169(62)$ & $39(14)$ \\
\hline
\end{tabular}

* Tumors can have more than 1 mutation in different exon and codon locations. Abbreviations: GI-gastrointestinal, GYN-gynecological.

genitourinary tumors (Supplemental - Figure 1e).

When all screened patients were considered, p53 mutations in the hot-spot codons $(175,245,248$, 249,273 , and 282) were significantly more common in colorectal cancer $(19 / 101,19 \%)$ than in the other tumor types $(33 / 580,6 \%)$. When the analysis was limited to patients with p53 mutations, 24 (49\%) patients with colorectal cancer had hot-spot mutations compared to 60 $(27 \%)$ patients with the remaining tumor types $(\mathrm{p}=.0002)$. Mutations in the DNA-binding domain excluding the hotspot codons were more commonly seen in ovarian and lung cancer (Supplemental-Figure 1a-1g).

\section{Other Aberrations}

We examined aberrations other than p53 in patients with p53 mutations and wild-type p53. Additional aberrations were found more often in the group with p53 mutations than in the wild-type $p 53$ group $(p=.002)$. The distribution of the number of other aberrations in the two groups is summarized in Table 3. Interestingly, PTEN loss or mutation was found more often in tumors with p53 mutations than in those with wild-type p53 (23\% vs. 5\%, $\mathrm{p}=.0005)$. Similarly, HER2 aberrations were significantly more common in tumors with p53 mutations than in those with wild-type p53 ( $8 \%$ vs. $2 \%, \mathrm{p}=.003$ ). Alternatively, there was a trend toward a higher percentage of $B R A F$ mutations in the patients with wild-type p53 compared with those with mutated p53 (6\% vs. $2 \%, \mathrm{p}=.07)$.

The distribution of the common additional aberrations in the groups of patients with mutant and wildtype p53 is summarized in Table 4. The most common additional aberrations seen in the mutant p53 group were PTEN (23\%), KRAS (16\%), APC (12\%), and PI3K (10\%). The most common aberrations seen in the wild-type p53 group were KRAS (16\%), PI3K (14\%), and PTEN (9\%). Overall, aberrations involved in the RAS/RAF/MEK pathway were more frequent in the p53 mutant group than in the wild-type p53 group (59/142 [42\%] vs. 81/258 [31\%], respectively; $p=.04)$. In contrast, no difference was observed between the two groups in aberrations involving the PI3K/AKT/mTOR pathway (56/142 [39\%] vs. 88/258 [34\%], respectively; $p=.29$ ).

\section{Treatment}

Of the 273 patients with p53 mutations, 195 (71\%) were treated on various phase I clinical trials; among them, $20(7 \%)$ patients received local therapy, including various hepatic arterial infusion and intra-peritoneal therapy regimens. The remaining 78 (29\%) patients did not receive any treatment for various reasons. Of 418 patients with wild-type p53, $312(75 \%)$ were treated on various phase I clinical trials; among them, $26(6 \%)$ patients received local therapy. The remaining 106 (25\%) patients did not receive any therapy. The reasons for which patients did not 
Table 3: Number of other aberrations associated with wild-type and mutant p53

\begin{tabular}{|l|l|l|l|}
\hline $\begin{array}{l}\text { No. of other } \\
\text { aberrations }\end{array}$ & $\begin{array}{l}\text { P53 mutation } \\
\mathrm{N}=273(\%)\end{array}$ & $\begin{array}{l}\text { P53 wild-type } \\
\mathrm{N}=418(\%)\end{array}$ & P-value \\
\hline 0 & $88(32.2)$ & $162(38.8)$ & \\
\cline { 1 - 3 } & $79(28.9)$ & $134(32.1)$ & \multirow{2}{*}{0018} \\
\cline { 1 - 3 } & $38(13.9)$ & $68(16.3)$ & \\
\hline 3 & $19(7.0)$ & $29(6.9)$ & \\
\hline
\end{tabular}

Table 4: Distribution of the most common other mutations associated with both wild-type and mutant p53 status

\begin{tabular}{|l|l|l|l|l|l|l|l|}
\hline & P53 mutation $(\mathrm{N}=273)$ & \multicolumn{3}{l|}{ P53 wild-type (N=418) } & P \\
\hline & Tested & Positive & $\%$ & Tested & Positive & $\%$ & \\
\hline PTEN* & 93 & 21 & 23 & 336 & 31 & 9 & .0005 \\
\hline PIK3CA & 263 & 26 & 10 & 388 & 55 & 14 & .10 \\
\hline BRAF & 250 & 6 & 2 & 329 & 18 & 6 & .07 \\
\hline KRAS $\S$ & 255 & 40 & 16 & 363 & 57 & 16 & 1.0 \\
\hline EGFR $\S$ & 241 & 9 & 4 & 334 & 7 & 2 & .24 \\
\hline c-Met & 254 & 9 & 4 & 370 & 11 & 3 & .69 \\
\hline HER2 $\S$ & 209 & 16 & 8 & 313 & 7 & 2 & .003 \\
\hline APC & 119 & 14 & 12 & 163 & 12 & 7 & .21 \\
\hline
\end{tabular}

*: PTEN loss by immunohistochemistry or mutation

$\S$ : Mutation or amplification.

receive treatment were ineligibility or unavailability of a clinical trial $(n=44,24 \%)$, insurance issues $(n=9,5 \%)$, and personal reasons $(\mathrm{n}=131,71 \%)$.

Among patients with additional aberrations in the p53 mutation group, 37 (26\%) patients received targeted therapy against the additional aberrations, 62 (43\%) patients received non-matched therapy, and 44 (31\%) patients received no therapy. In the wild-type p53 group,
$78(30 \%)$ patients received targeted therapy against the additional aberrations, 117 (45\%) patients received nonmatched therapy, and $63(25 \%)$ patients received no therapy.
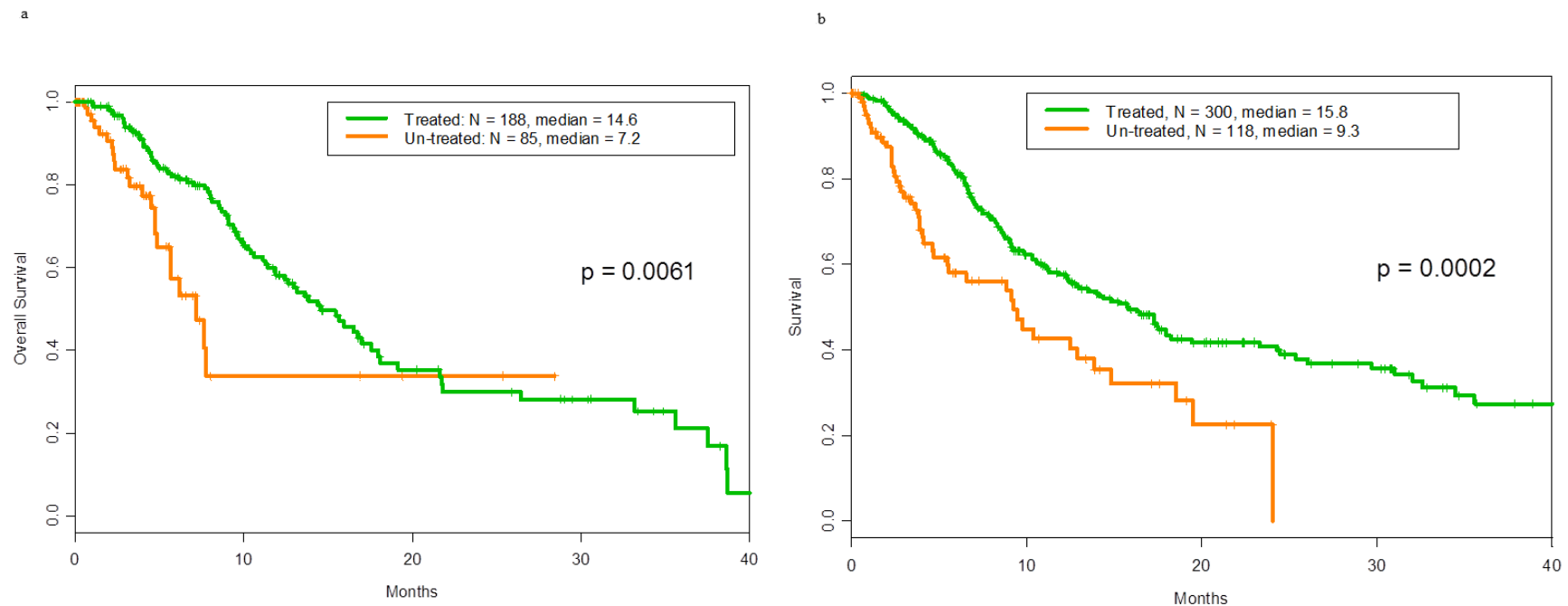

Figure 1: a Overall survival of patients with mutant p53 tumors by whether they did or did not receive any treatment in phase I. Of 188 patients treated with phase 1 trials the median overall survival was 14.6 months. Of 85 patients non-treated the median overall survival was 7.2 months.b. Overall survival of patients with wild-type p53 tumors by whether they did or did not receive any treatment in phase I. Of 300 patients treated with phase 1 trials the median overall survival was 15.8 months. Of 118 patients non-treated the median overall survival was 9.3 months. 


\section{Overall Survival}

There was no difference in overall survival between patients with p53 mutations and those with wild-type p53 (median survival, 14 months, 95\% confidence interval: 1117 , for both groups; hazard ratio $=1.0,95 \%$ confidence interval: $0.8-1.3 ; \mathrm{p}=.71$ ). The overall survival of treated and untreated patients with p53 mutations is shown in Figure 1a. The median survival durations were 14.6 months and 7.2 months, respectively $(\mathrm{p}=.006)$. The overall survival of treated and untreated patients with wild-type p53 is shown in Figure 1b. The median survival durations were 15.8 months and 9.3 months, respectively $(\mathrm{p}=.0002)$.

The overall survival of patients with p53 mutations by exon is shown in Supplemental-Figure 2. The median overall survival durations for exon 5, 6, 7, and 8 mutations were $9.5,13.6,15.7$, and 17.6 months, respectively $(\mathrm{p}=.31)$.

\section{Overall Survival by p53 Status and Additional Aberrations}

We performed survival analyses of patients with p 53 mutations and additional aberrations. The median survival durations were 13.6 months in patients who received matched therapy $(\mathrm{n}=37), 13.9$ months in those who received non-matched therapy $(\mathrm{n}=62)$, and 7.6 months in those who received no treatment $(n=44)(p=.06$; Figure 2a). In multivariate analyses (in which performance status [0 vs. $\geq 1]$, serum albumin level $[<3.5 \mathrm{~g} / \mathrm{dL}$ vs. $\geq 3.5 \mathrm{~g} / \mathrm{dL}]$, lactate dehydrogenase level $[<617 \mathrm{U} / \mathrm{L}$ vs. $\geq 617 \mathrm{U} / \mathrm{L}]$, number of metastatic sites [0-2 vs. $\geq 3]$, liver metastases, and number of prior treatments [0-3 vs. $\geq 4]$ were taken into consideration), no significant difference in survival was noted among the three groups $(\mathrm{p}=0.15)$.

In patients with wild-type p53 and other aberrations, those treated with matched therapy $(n=78)$ had longer survival than those treated with non-matched therapy $(\mathrm{n}=$ $117)$ or those who received no treatment $(n=63)$ (median survival, 26.0 vs. 11.8 vs. 9.8 months, respectively; $\mathrm{p}=$ .0007 ; Figure 2b).

A multivariate analysis (after adjustment for the variables listed above) confirmed this difference between the treatment groups $(\mathrm{p}=.0002)$. These findings translated into longer survival for the patients with a more number of additional mutations in the wild-type p53, but not the mutant p53 group (Supplemental-Figure 3a and 3b).

\section{DISCUSSION}

This analysis expands on our previous report on the characteristics and survival of patients with advanced cancer and p53 mutations. In the current study, we evaluated the effects of specific p53 mutations and additional aberrations on survival in patients referred to the Phase I Clinical Trials Program. P53 mutations were associated with higher numbers of other aberrations and resistance to targeted therapy. P53 status did not affect overall survival in this patient population, but matched therapy for other aberrations was associated with longer survival in patients with wild-type p53. P53 mutations varied by tumor type and were associated with higher proportions of PTEN and HER2 aberrations than wildtype $\mathrm{p} 53$.

Overall, $39.5 \%$ of the patients analyzed had a p53 mutation. Patients with p53 mutations were older $(\mathrm{p}<.0001)$ and had higher rates of hepatic metastases $(\mathrm{p}=.005)$ than patients with wild-type $\mathrm{p} 53$. P53 mutations within exon 5 were more common in colorectal cancer,
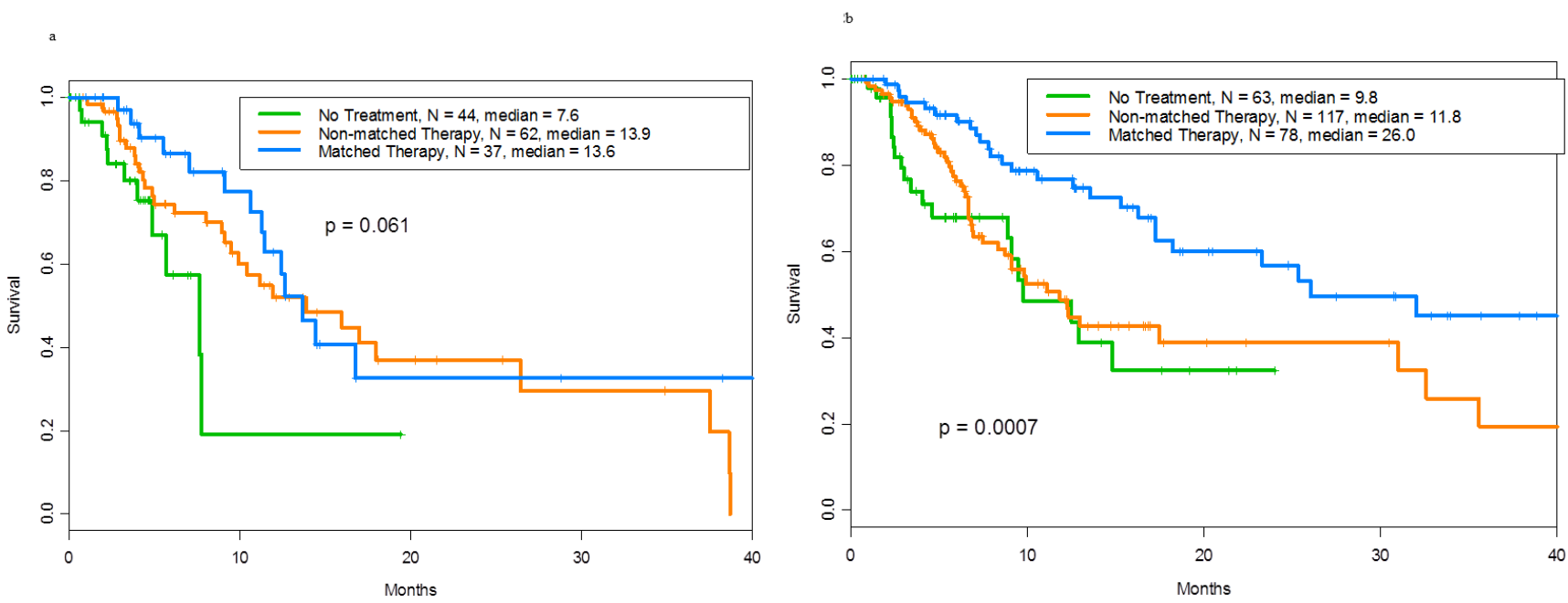

Figure 2: a Overall survival of patients with mutant $\mathrm{p} 53$ tumors by whether they received matched targeted therapy ( $\mathrm{n}=37)-$, non-matched $(\mathrm{n}=62)-$, or no therapy $(\mathrm{n}=44)$ for the other aberrations with a median survival of $13.6,13.9$ and 7.6 months, respectively. b.Overall survival of patients with wild-type $\mathrm{p} 53$ tumors by whether they received matched targeted therapy ( $\mathrm{n}=78)$ ), nonmatched ( $\mathrm{n}=117)$-, or no therapy ( $\mathrm{n}=63)$ for the other aberrations with a median survival of $26,11.8$ and 9.8 months, respectively. 
while mutations within exons 6,7 , and 8 were more common in lung, pancreatic, and ovarian cancer, respectively.

Our findings of older age, more frequent liver metastases, and more frequent PTEN loss in the p53mutated group in the current, more extensive analysis, were similar to those in our prior analysis [15].

Our results are consistent with previously known data showing that the percentage of p53 mutation varies by tumor type and ranges from $10 \%$ to $80 \%$ [16]. Our results are also in line with a previous study showing that p53 mutations occurred more frequently in older patients with rectal cancer [17]. Other investigators have reported that breast cancers harboring p53 mutations occur more often in young women (age $\leq 40$ years at diagnosis)[18]. In the latter study p53 mutations were found in $63.8 \%$ of patients, and the percentage of patients with triple negative breast cancer was not reported.

The observation that patients with p53 mutations had more liver metastases may be partially explained by the role of mutant p53 in promoting cell migration and invasion [19], as shown in preclinical models [11, 20]. A previous study showed that patients with colorectal cancer with p53 mutations had a larger number of hepatic metastases than patients with wild-type p53 tumors [21].

The distribution of various types of p53 mutations in our study varies by tumor type. This difference may contribute to the variable prognostic value of p53 mutations in various tumor types with p53 mutations [13].

In our series, tumors with p53 mutations had more additional aberrations than tumors with wild-type p53 $(\mathrm{p}=.002)$ (Table 3$)$. We found that loss of PTEN or PTEN mutation $(23 \%$ vs. $5 \%, \mathrm{p}=.0005)$ and HER2 aberrations ( $8 \%$ vs. $2 \%, p=.003$ ) were more common in tumors with p53 mutations than in those with wild-type p53. These results may be due in part to the role of p53 in maintaining genomic integrity in mammalian cells, as previously described [22]. The frequency of PTEN aberrations in tumors with p53 mutations further supports the need for "individualized" treatment targeting the PI3K/AKT/PTEN pathway in prospective clinical trials.

No difference in survival was observed between patients with p53 mutations and those with wild-type p53 $(p=0.71)$. In both groups, the overall survival duration was longer in patients who received treatment than in those who did not. However, among patients with wildtype p53 and other aberrations, survival was superior in those who received matched therapy against the additional aberrations compared to non-matched therapy. We have previously published evidence that identifying specific molecular abnormalities and choosing therapy based on these abnormalities is associated with a longer time to treatment failure in the phase I setting than that of previous systemic therapy. Furthermore, in the non-randomized setting, rates of response, time to treatment failure, and survival were higher with matched targeted therapy than with non-matched therapy [23].

An intriguing finding in the current report is the observation that patients with wild-type p53 and other aberrations who received matched therapy against these aberrations had longer survival than those treated with non-matched therapy or those who received no treatment (median survival, 26 vs. 11.8 vs. 9.8 months, respectively; $\mathrm{p}=.0007)$. This survival advantage was confirmed in multivariate analysis after adjustment for other covariates $(p=.0002)$. In contrast, in the p53 mutation group with additional aberrations, the survival durations were similar for those who received matched therapy against the additional aberrations, those treated with non-matched therapy, and those who received no therapy (median survival, 13.6 vs. 13.9 vs. 7.6 months, respectively; $\mathrm{p}=.06)$.

The exact role of p53 in the context of other molecular aberrations and their prognostic significance in various tumor types needs to be elucidated. Whether p53 mutations are driver mutations or contribute to the emergence of resistance to targeted agents needs to be evaluated. Resistance to therapy seen in tumors with p53 mutation requires the development of new agents or strategies. Several investigators have reported that p53based cyclotherapy may represent a successful strategy. [24-30] This approach is based on protection of normal cells from chemotherapy-induced adverse events. Lowdoses of p53 activators, such as nutlin-3 and actinomycin $\mathrm{D}$, are used to induce p53-dependent cell cycle arrest in normal cells bearing wild-type p53. [24-30] Prospective clinical trials are needed to explore the role of this approach in overcoming p53 resistance.

Our data suggest that the identification of driver mutations in patients with wild-type p53 and other aberrations and the selection of targeted therapy may contribute to improved survival. Recently published data in head and neck squamous cell carcinoma also demonstrated that PI3K/Akt/mTOR inhibition using PF04691502 is enhanced with induction of wild-type p53 in human xenograft and murine knockout models [31]. The authors concluded that p53 is one of the potential modifiers of response (in addition to PI3KCA, PTEN, TGF- $\beta$ alterations) [31].

In conclusion, our data add to the published data demonstrating that p53 mutations are associated with a poor prognosis and resistance to treatment, and they emphasize the need to develop agents or strategies to overcome this resistance. These findings further support the need to individualize cancer therapy and should be validated in carefully designed prospective trials. 


\section{METHODS}

\section{Patients}

We reviewed all patients who underwent testing for p53 mutation status in the Department of Investigational Cancer Therapeutics at MD Anderson Cancer Center. Molecular profiling was performed on available tissue samples from consecutive patients with advanced tumors referred to the Clinical Center for Targeted Therapy. Patients were of various ages and had advanced or metastatic cancer that was refractory to standard therapy, that had relapsed after standard therapy, or for which there was no standard therapy available. All protocols required that participants have evidence of evaluable or measurable disease according to Response Evaluation Criteria in Solid Tumors (RECIST) guidelines [32, 33] and an Eastern Cooperative Oncology Group performance status of $0-2$. Additional eligibility criteria varied by protocol. All patients provided written informed consent prior to enrollment in a trial. All trials, as well as this analysis, were performed with the approval of and in accordance with the guidelines of the MD Anderson Institutional Review Board.

\section{Analysis of Molecular Aberrations}

The $\mathrm{p} 53$ mutation status was determined by either polymerase chain reaction-based or next-generation sequencing in a Clinical Laboratory Improvement Amendments-certified laboratory, as previously described [23]. The next-generation sequencing included 182 genes in targeted next-generation sequencing Foundation One platform (Foundation Medicine, Cambridge, MA).

\section{Therapy}

Treatment was selected as previously published [23]. Briefly, the allocation of patients to investigational treatment varied over time according to protocol availability, eligibility criteria, histologic diagnosis, the patient's prior response to therapy, potential toxicity, insurance coverage, and patient preference or physician choice. The assignment to a clinical trial was determined after clinical, laboratory, and pathologic data from all available patient records were reviewed. Patients whose tumors had a molecular aberration were treated on a clinical trial with a matched targeted agent, when available.

\section{Endpoints and Statistical Methods}

Patients' characteristics were analyzed using descriptive statistics. Categorical data were described using contingency tables, including counts and percentages. Continuously scaled measures were summarized by median and range. The association between two categorical variables was examined using the chi-square test. Survival and hazard functions were estimated using the Kaplan-Meier method, and survival between groups was compared using the two-sided logrank test. Survival was analyzed according to the type of p53 mutations and the treatment. Hazard ratios with and without adjustment for potential confounding variables were estimated using Cox proportional hazard regression analysis.

\section{ACKNOWLEDGMENTS}

The authors are thankful for Ms. Christine Eberle for her assistance with submission of the manuscript.

This work was presented at ASCO annual meeting June 2013, Abstract \# 115369. This study was funded by the Alberto Barretto Donor Fund to Dr. A. M. Tsimberidou Authors have no conflict to report.

\section{REFERENCES}

1 Brown CJ, Lain S, Verma CS, Fersht AR, Lane DP. Awakening guardian angels: drugging the p53 pathway. Nature reviews Cancer. 2009;9:862-73.

2 Girardini JE, Napoli M, Piazza S, Rustighi A, Marotta C, Radaelli E, et al. A Pin1/mutant p53 axis promotes aggressiveness in breast cancer. Cancer Cell. 2011;20:7991.

3 Muller PA, Caswell PT, Doyle B, Iwanicki MP, Tan EH, Karim S, et al. Mutant p53 drives invasion by promoting integrin recycling. Cell. 2009;139:1327-41.

4 Adorno M, Cordenonsi M, Montagner M, Dupont S, Wong C, Hann B, et al. A Mutant-p53/Smad complex opposes p63 to empower TGFbeta-induced metastasis. Cell. 2009; 137:87-98.

5 Lang GA, Iwakuma T, Suh YA, Liu G, Rao VA, Parant JM, et al. Gain of function of a p53 hot spot mutation in a mouse model of Li-Fraumeni syndrome. Cell. 2004;119:861-72.

6 Olive KP, Tuveson DA, Ruhe ZC, Yin B, Willis NA, Bronson RT, et al. Mutant p53 gain of function in two mouse models of Li-Fraumeni syndrome. Cell. 2004;119:847-60.

7 Muller PA, Trinidad AG, Timpson P, Morton JP, Zanivan $\mathrm{S}$, van den Berghe PV, et al. Mutant p53 enhances MET trafficking and signalling to drive cell scattering and invasion. Oncogene. 2013;32:1252-65.

8 Liu K, Ling S, Lin WC. TopBP1 mediates mutant p53 gain 
of function through NF-Y and p63/p73. Mol Cell Biol. 2011;31:4464-81.

9 Irwin MS, Kondo K, Marin MC, Cheng LS, Hahn WC, Kaelin WG, Jr. Chemosensitivity linked to p73 function. Cancer Cell. 2003;3:403-10.

10 Moll UM, Erster S, Zaika A. p53, p63 and p73--solos, alliances and feuds among family members. Biochim Biophys Acta. 2001;1552:47-59.

11 Caulin C, Nguyen T, Lang GA, Goepfert TM, Brinkley BR, Cai WW, et al. An inducible mouse model for skin cancer reveals distinct roles for gain- and loss-of-function p53 mutations. The Journal of clinical investigation. 2007; 117:1893-901

12 Hingorani SR, Wang L, Multani AS, Combs C, Deramaudt TB, Hruban RH, et al. Trp53R172H and KrasG12D cooperate to promote chromosomal instability and widely metastatic pancreatic ductal adenocarcinoma in mice. Cancer Cell. 2005;7:469-83.

13 Robles AI, Harris CC. Clinical outcomes and correlates of TP53 mutations and cancer. Cold Spring Harbor perspectives in biology. 2010;2:a001016.

14. Petitjean A, Achatz MI, Borresen-Dale AL, Hainaut P, Olivier M. TP53 mutations in human cancers: functional selection and impact on cancer prognosis and outcomes. Oncogene. 2007;26:2157-65.

15 Said R, Hong DS, Warneke CL, Lee JJ, Wheler JJ, Janku F, et al. P53 Mutations in Advanced Cancers: Clinical Characteristics, Outcomes, and Correlation between Progression-Free Survival and Bevacizumab-Containing Therapy. Oncotarget. 2013;4:705-14.

$16 \mathrm{http}: / / \mathrm{p} 53$. free.fr/index.html.

17 Servomaa K, Kiuru A, Kosma VM, Hirvikoski P, Rytomaa T. p53 and K-ras gene mutations in carcinoma of the rectum among Finnish women. Molecular pathology : MP. 2000;53:24-30.

18 Lai H, Lin L, Nadji M, Lai S, Trapido E, Meng L. Mutations in the p53 tumor suppressor gene and early onset breast cancer. Cancer biology \& therapy. 2002;1:31-6.

19 Muller PA, Vousden KH, Norman JC. p53 and its mutants in tumor cell migration and invasion. The Journal of cell biology. 2011;192:209-18.

20 Liu G, McDonnell TJ, Montes de Oca Luna R, Kapoor M, Mims B, El-Naggar AK, et al. High metastatic potential in mice inheriting a targeted p53 missense mutation. Proceedings of the National Academy of Sciences of the United States of America. 2000;97:4174-9.

21 Tullo A, D'Erchia AM, Honda K, Mitry RR, Kelly MD, Habib NA, et al. Characterization of p53 mutations in colorectal liver metastases and correlation with clinical parameters. Clinical cancer research : an official journal of the American Association for Cancer Research. 1999;5:3523-8.

22 Agapova LS, Ilyinskaya GV, Turovets NA, Ivanov AV, Chumakov PM, Kopnin BP. Chromosome changes caused by alterations of p53 expression. Mutation research. 1996;354:129-38.

23 Tsimberidou AM, Iskander NG, Hong DS, Wheler JJ, Falchook GS, Fu S, et al. Personalized medicine in a phase I clinical trials program: the MD Anderson Cancer Center initiative. Clinical cancer research : an official journal of the American Association for Cancer Research. 2012;18:637383.

24 Blagosklonny MV. Sequential activation and inactivation of G2 checkpoints for selective killing of p53-deficient cells by microtubule-active drugs. Oncogene. 2002;21:6249-54.

25 Sur S, Pagliarini R, Bunz F, Rago C, Diaz LA, Jr., Kinzler $\mathrm{KW}$, et al. A panel of isogenic human cancer cells suggests a therapeutic approach for cancers with inactivated p53. Proceedings of the National Academy of Sciences of the United States of America. 2009;106:3964-9.

26 Apontes P, Leontieva OV, Demidenko ZN, Li F, Blagosklonny MV. Exploring long-term protection of normal human fibroblasts and epithelial cells from chemotherapy in cell culture. Oncotarget. 2011;2:222-33.

27 Rao B, Lain S, Thompson AM. p53-Based cyclotherapy: exploiting the 'guardian of the genome' to protect normal cells from cytotoxic therapy. British journal of cancer. 2013;109:2954-8.

28 van Leeuwen IM, Rao B, Sachweh MC, Lain S. An evaluation of small-molecule p53 activators as chemoprotectants ameliorating adverse effects of anticancer drugs in normal cells. Cell cycle. 2012;11:1851-61.

29 Rao B, van Leeuwen IM, Higgins M, Campbel J, Thompson AM, Lane DP, et al. Evaluation of an Actinomycin D/ VX-680 aurora kinase inhibitor combination in p53-based cyclotherapy. Oncotarget. 2010;1:639-50.

30 van Leeuwen IM. Cyclotherapy: opening a therapeutic window in cancer treatment. Oncotarget. 2012;3:596-600.

31 Herzog A, Bian Y, Vander Broek R, Hall B, Coupar J, Cheng H, et al. PI3K/mTOR Inhibitor PF-04691502 Antitumor Activity Is Enhanced with Induction of WildType TP53 in Human Xenograft and Murine Knockout Models of Head and Neck Cancer. Clinical cancer research : an official journal of the American Association for Cancer Research. 2013;19:3808-19.

32 Therasse P, Arbuck SG, Eisenhauer EA, Wanders J, Kaplan RS, Rubinstein L, et al. New guidelines to evaluate the response to treatment in solid tumors. European Organization for Research and Treatment of Cancer, National Cancer Institute of the United States, National Cancer Institute of Canada. J Natl Cancer Inst. 2000;92:20516.

33 Eisenhauer EA, Therasse P, Bogaerts J, Schwartz LH, Sargent D, Ford R, et al. New response evaluation criteria in solid tumours: revised RECIST guideline (version 1.1). Eur J Cancer. 2009;45:228-47. 